\title{
STUDIES ON SELECTED PROTEINS OF BONE IN ARCHAEOLOGY
}

\author{
HARRY SOBEL ${ }^{1}$ and RAINER BERGER
}

Isotope and Archeometry Laboratory, Institute of Geophysics and Planetary Physics University of California, Los Angeles, California 90024 USA

\begin{abstract}
With the advent of AMS radiocarbon dating of very small samples, a much greater opportunity now exists for research into specialized materials. Investigations of the proteins of bone and teeth for archaeological purposes suggest that much more information might be obtained by appropriate study of individual proteins in these tissues. Although present research seems limited to ${ }^{14} \mathrm{C}$ dating, racemization and dietary selection, conditions of the environment during preservation and some of the physiological events during life are likely to be discernible through further studies.
\end{abstract}

\section{INTRODUCTION}

Bones and teeth are the most resistant tissues in the remains of an organism. In the living state, they contain leaked plasma proteins, the marrow constituents and the organic matrix in which the inorganic constituents of bone are deposited. With the advent of accelerator mass spectrometric (AMS) dating of milligram-sized samples, it may become possible to carry out the ideal of learning about the physiological state of the donor during life and the history of the residue after death.

Bone contains mainly hydroxyapatite crystals, which are laid down in a matrix of type-I collagen fibers. Collagen makes up $90 \%$ of the organic matrix of dried, defatted bone. Several non-collagenous proteins make up the remainder. Up to 200 (Delmas et al. 1984) have been detected but few have been identified. Most may be modified forms of the primary proteins. Some are thought to serve in osteoblastic and osteoclastic function and relate to nutritional and endocrine factors. We discuss our experience with collagen and osteocalcin and our thoughts about the utility of other proteins found in bone, including ferritin.

\section{DESCRIPTIVE BACKGROUND}

The interest of one of us (H.S.) in bone proteins stems from the time when Fuller Albright came to McGill University to lecture on osteoporosis in 1945. Through the ensuing years, this developed into a career in the investigation of the role of connective tissue constituents (proteins) in physiological aging. Now we have extended our interest to the environmental aging of proteins in diagenesis.

In the course of an investigation on the histological characteristics of collagen in the sun-exposed face, an attempt was made to simulate this change in-vivo, then in-vitro, on the basis of a free-radical effect. The yellowing and fluorescence of collagen in some elderly persons seemed to be replicated on exposure of acid-soluble collagen from infant mice who had been labeled with ${ }^{14} \mathrm{C}$-tyrosine to oxygen under high pressure. The product, oxygen-modified collagen (OMC), was no longer soluble in hot water and was yellow and fluorescent (Puleo and Sobel 1972). Some of the radioactive tyrosine was found as dityrosine, a marker for free radicals. Now OMC seems to be present in Dead Sea Scroll parchment collagen, and dityrosine was also detected (Sobel and Ajie 1992). Thus, the fate of collagen in ancient materials over historic time is of great interest to us.

One of us (H.S.) was asked to principally supervise Henry Ajie of UCLA in his doctoral work involving the use of bone collagen in dietary studies. When he found that some specimens of bone had little or no collagen we offered our knowledge of non-collagen proteins in bone, and suggested

\footnotetext{
${ }^{1}$ Deceased 25 August 1994
} 
that he look into osteocalcin, referring to its presence in very old bone, thus demonstrating its far greater stability in this tissue. His success with this protein opened a new door to several fields of study (Ajie 1991).

Proteins have been used in archaeology for the purpose of dating organic residues through ${ }^{14} \mathrm{C}$ and racemization studies. Stable isotopic analysis has been used for dietary investigations. Our experience leads us to argue that if the fate of historic proteins were studied individually in greater detail, by observing and interpreting the diagenic changes, one might better glimpse the history of the environment after time of deposition of the object. Further, with "reconstitution" of several proteins to the living state, it might be possible to learn something about the physiological state of the donor: perhaps the hormonal and nutritional status, for that is what a "fresh" bone can tell.

\section{Discussion}

\section{Collagen}

Collagen is probably the most studied protein of our time. Its genetic control and post-translational genetically directed modifications result in the cross-linked, triple-stranded coils that give connective tissues their toughness and flexibility and lead to its maturation (Nimni 1988-1989). Environmentally induced alterations can also occur. Although it was once thought that "mature" collagen did not turn over, we now know that local restructuring of tissue can modify, remove and deposit collagen as needed. Nevertheless, it exhibits the lowest turnover among proteins (Libby et al 1964; Berger, Fergusson and Libby 1965). We have speculated that environmental modifications during life and after death, as long as its primary form is maintained, may contain clues to its history. Bone resorption under physiological and pathological conditions has been under intensive study for a considerable time, and this includes the fate of the collagen. These events are controlled by dietary, humoral and enzymatic factors (Noda 1993).

Diagenic modification of bone is dominated by biogenic attack, but under certain circumstances of burial, including relatively low humidity and moderate temperature, preservation of organic constituents may be adequate. Collagen in parchment may offer an opportunity to study its resistance to an environment with minimal variables, because when used as scriptural material, it is greatly valued and protected. It is, however, exposed to the atmosphere (and therefore oxygen), humidity variation, solar and background radiation and sundry environmental constituents carried by persons who inspect or touch it, such as tobacco or alcohol. The cave-hidden Dead Sea Scroll parchment is 2000yr-old collagen exposed minimally to variations in the atmosphere, relatively constant humidity and temperature and elements of superficial tanning originally applied in its preparation.

Humidity plays an important role in the fate of collagen. Variations in humidity levels can result in swelling and shrinking of collagen fibers-the breaking and reformation and misalignment of hydrogen bonds. This results in the distortion of the $640 \AA$ electron micrograph banding and increased susceptibility to further deterioration. Hansen, Lee and Sobel (1992) suggested that a humidity of $30-50 \%$ minimizes the effects of humidity variations on parchment.

The importance of atmospheric oxygen operating over long periods of time seems evident. Sobel and Ajie (1992) also showed that $96 \%$ of extracted protein from modern parchment is collagen, but only $67 \%$ was recovered from the Dead Sea Scroll material. The residue seemed to resemble the material found in OMC, but this has not yet been verified. This material requires further study. It appears that the residual material was converted to a higher molecular weight protein, but it yields the correct amino acid analysis for collagen. Higher molecular weight material in collagen has been noted 
before. Tuross et al. (1978) state that "derived crosslinks in the collagen molecule may play a role in stabilizing the breakdown products. It is also possible that additional crosslinking may occur in the geologic setting". Stadman (1993) reported that radiolysis in the absence of oxygen may generate higher molecular weight protein aggregates owing partly to the generation of interprotein crosslinking reactions.

We ask whether there is a general pattern for the diagenic behavior of individual proteins. While a portion is broken down into products of lower molecular weight and is subject to easy removal, say by water, a fraction is also being slowly modified by oxygen, but at a constant rate, to a product of higher molecular weight.

To study this, we must consider two possibilities: 1) as with parchment, the material is "protected" and remains compacted, and oxygen-modified protein (OMP) accrues without removal of the degraded material; and 2) as with bone, the hydrolytically deteriorated protein is "washed away" leaving the as-yet unmodified protein and OMP. The OMP may not be as readily definable as OMC, and it would have to be characterized and identified; nor would it necessarily be one substance.

We must expose a given protein to oxygen under controlled (hyperbaric) conditions and "simulate" the passage of time, investigate and identify the OMPs, and finally, locate naturally "aged" protein. One could then set up a co-dating scale relating OMPs with the ${ }^{14} \mathrm{C}$ date, actually, the ratio OMP/ unchanged protein $v s .{ }^{14} \mathrm{C}$ date. In use, if the dates do not agree, environmental variables, such as temperature differences from the controlled state, may exist.

In the case of buried bone, gelatinized material and hydrolic products may have washed away, leaving unchanged collagen and OMC. The amount of material that has been washed away can be calculated from the ${ }^{14} \mathrm{C}$ date and the ratio of $\mathrm{OMC} /$ collagen.

We summarize this discussion of collagen with the observation that collagen observed in archaeological bone uncommonly exhibits its intact native composition, which has been subjected to swelling, shrinking, gelation and hydrolytic processes. Insufficient attention has been given collagen fragments, which may be caused by non-random processes. Chemical examination of the protein fragments, the unchanged collagen and the OMC will lead to far greater insight into the history of the donor as well as the bones after burial. For example, glucose can react non-enzymatically with amino groups of proteins to some extent with the initial formation of a Schiff-base followed by an Amadori rearrangement. Oxidation of this product leads to more permanent irreversible modifications and cross-links. Many proteins, including collagen, exhibit some degree of glycosylation. Diabetes will result in greater levels of glycosylation as a result of time-averaged long-term plasma glucose concentration. Long-lived proteins, such as collagen, exhibit the presence of diabetes in the subject (Fu et al. 1994).

Alcohol has been linked to human cultures since the agricultural revolution. We believe it is possible to obtain evidence of this coexistence from collagen (Tuma, Hoffman and Sorrel 1991), but we do not know how stable these products are over time. Results of collagen studies on burned bone are inconclusive.

\section{Osteocalcin}

Many non-collagenous proteins have been detected in the organic matrix of bone, but only a few have been the subject of intensive study. To be of interest to archaeologists and archaeometrists, non-collagenous proteins must be present in detectable quantities, endure burial and offer advantages with further study. To be persistent, the protein requires an affinity for apatite crystals. At 
present, only one protein seems to possess the nectssary stability-osteocalcin. This protein has been detected in bone $13 \mathrm{Myr}$ old. Ajie (1991) has also demonstrated that this substance may be useful for ${ }^{14} \mathrm{C}$ dating. For it to be suitable for dietary study, the essential amino acids must be isolated.

Osteocalcin constitutes $c a .15 \%$ of the non-collagen bone-matrix protein. It is a highly conserved protein consisting in the human of a single chain of 49 amino acids with a calculated molecular weight of 5879 Daltons (Price et al. 1976). Two of the glutamic acid residues have been carboxylated in the $\gamma$ position; hence, the designation, bone "Gla" protein. This carboxylation is vitamin-Kdependent (Poser et al 1980). Vitamin $\mathrm{D}_{3}$ also regulates osteocalcin synthesis (Price and Baukol 1981). The utility of isolated osteocalcin for ${ }^{14} \mathrm{C}$ dating has been demonstrated, but the fate of the native protein in bone suggests extensive diagenesis. Radioimmunoassay suggests that the fossil human bones retained only a fraction of unmodified in-vivo osteocalcin compared with the content of modern bone (Ajie et al. 1991). Osteocalcin contains 5 of its 49 amino acids as tyrosine as well as several other oxidizable amino acids. Perhaps an oxygen-modified osteocalcin (OMO) should be sought. Interestingly, osteocalcin also becomes increasingly glycosylated with diabetes and with increasing age (Gundberg et al. 1986).

Several other proteins, whose physiological roles have been identified, might also be useful in archaeology if they proved resistant enough to remain detectable. These include osteopontin, bone sialoprotein, biglycin, decorin, osteonectin, fibronectin and several variants (Termine 1993). Some do not occur exclusively in bone. Several are phosphorylated and sulphated and could have a strong affinity for bone. Others are classified as sialoproteins and proteoglycans. If they could be detected and quantitatively determined, correcting for the degree of diagenesis, one might learn a great deal about the physiology of the living donor, including nutritional and endocrine history.

\section{Ferritin}

Ferritin is another interesting protein. The marrow contains numerous proteins related to its functions, which include hematopoietic tissue and leaked plasma proteins. Tuross and Stathpolos (1993) report that ancient bones contain albumin and immunoglobulins. Ferritin, an iron-storage protein (Theil 1987) is also present in bone marrow, but has not yet been investigated in ancient bone. A study of this protein and its diagenesis may help to determine the presence of iron-deficiency anemia as a cause of certain "disappeared populations", especially those persisting on a grossly vegetarian diet (Dallman 1990). Ferritin contains as much as $23 \%$ iron in the form of a colloidal ferric hydroxide-ferric phosphate complex bound firmly in its shell of protein apoferritin. We propose to study this protein in intact bones from burials. Broken bones may pose a problem due to contamination and solubility. The isotopic composition of the iron moiety has yet to be investigated as well.

\section{CONCLUSION}

Whereas archaeology today depends mainly on the discovery, assembly and associated measurement of humans and their artifacts, in the future, it may include, to a much greater extent, results based on data extracted from physiological, nutritional, endocrinological and pathological studies. Inasmuch as milligram and submilligram sample sizes are now datable by AMS, very specific biochemical samples are now suitable for analysis directly, which would not only reveal the samples' calendric ages, but also certain environmental conditions related to the donors or their environments. We have discussed the usefulness of collagen, osteocalcin, ferritin and other proteins for such studies as prehistoric environmental conditions, alcohol use and iron-deficiency anemia, to name a few. There are, certainly, other indicators available for scientific study by prehistorians. 


\section{ACKNOWLEDGMENTS}

We are grateful to Anthony Regan, UCLA Geology Library, for his assistance. This is publication No. 4270 of the Institute of Geophysics and Planetary Physics.

\section{REFERENCES}

Ajie, H. O. (ms.) 1991 Comparison of bone collagen for determination of radiocarbon ages and paleodietary reconstruction. Ph.D. dissertation, University of California, Los Angeles: $140 \mathrm{p}$.

Ajie, H. O., Hauschka, P. V., Kaplan, I. R. and Sobel, H. 1991 Comparison of bone collagen and osteocalcin for determination of radiocarbon ages and paleodietary reconstruction. Earth and Planetary Science Letters 107(2): 380-388.

Berger, R., Fergusson, G. J. and Libby, W. F. 1965 UCLA radiocarbon dates IV. Radiocarbon 7: 336-371.

Dallman, R. P. 1990 Iron. In M. L. Brown, ed., Present Knowledge of Nutrition, 6 th edition. Washington, D.C., Nutritional Foundation: 241-260.

Delmas, P. D., Tracy, R. P., Riggs, B. L. and Mann, K. G. 1984 Identification of the noncollagenous proteins of bovine bone by two dimensional gel electrophoresis. Calcified Tissue Research 36(3): 308-316.

Fu, M. X., Wella-Knecht, F. J., Blackledge, A., Lyons, T. J., Thorpe, S. R. and Baynes, J. W. 1994 Glycation, gloxidation and cross-linking of collagen by glucose. Kinetics, mechanisms and inhibition of late stages of the Mailard Reaction. Diabetes 43(5): 676-683.

Gundberg, C. M., Anderson, M., Dickson, I. and Gallop, P. M. 1986 "Glycated" osteocalcin in human and bovine bone. Journal of Biochemical Chemistry 261(1) 14557-14561.

Hansen, E. F., Lee, S. N. and Sobel, H. 1992 The effects of relative humidity on some physical properties of modern vellum: Implications for the optimum relative humidity for the display and storage of parchment. Journal of the American Institute for Conservation 31(3): 325-342.

Libby, W. F., Berger, R., Mead, J. F., Alexander, G. V. and Ross, J. F. 1964 Replacement rates for human tissue from atmospheric radiocarbon. Science 146(3648): 1170-1172.

Mimni, M. E., ed., 1988-1989 Collagen V1-5. Boca Raton, Florida, CRC Press.

Noda, M., ed., 1993 Cellular and Molecular Biology of Bone. San Diego, Academic Press: 1-567.
Poser, J. W., Esch, F. S., Ling, N. C. and Price, P. A. 1980 Isolation and sequence of the vitamin K-dependent bone protein. Journal of Biological Chemistry 255 (18): 8685-8691.

Price, P. A. and Baukol, S. 1981 1,25-dihydroxy vitamin $\mathrm{D}_{3}$ increases serum levels of the vitamin K-dependent bone protein. Biochemical and Biophysical Research Communications 99(3): 928-933.

Price, P. A., Poser, J. W. and Ramon, N. 1976 Primary structure of the $\gamma$-carboxy glutamic acid-containing protein from bovine bone. Proceedings of the National Academy of Sciences 73(10): 3374-3375.

Puleo, L. E. and Sobei, H. 1972 Oxygen-modified collagen and its possible pathological significance. Aerospace Medicine 43(4): 429-431.

Sobel, H. and Ajie, H. 1992 Modification in amino acids of Dead Sea Scroll parchments. Free-Radical Biology and Medicine 13(6): 701-702.

Stadman, E. R. 1993 Oxidation of free amino acids and amino acid residues in proteins by radiolysis and by metal catalyzed reactions. In Annual Reviews of Biochemistry 62: 797-821. Palo Alto, California, Annual Reviews Inc.

Termine, J. D. 1993 Bone matrix proteins and the mineralization process. In Favus, M. J., ed., Primer on the Metabolic Bone Diseases and Disorders of Mineral Metabolism. New York, Raven Press: 21-25.

Theil, E. C. 1987 Ferritin: Structure, gene regulation and cellular function in animals, plants and microorganisms. In Annual Reviews of Biochemistry 56: 289315. Palo Alto, California, Annual Reviews Inc.

Tuma, D. J., Hoffman, T. and Sorrel, M. F. 1991 The chemistry of acetaldehyde-protein adducts. Alcohol Alcoholism, Supplement 1: 271-276.

Tuross, N., Eyre, D. R., Holtrop, M. E., Glimcher, M. J. and Hare, P. E. 1978 Collagen in fossil bones. In Hare, P. E., ed., Biochemistry in Amino Acids. New York, John Wiley \& Sons: 53-63.

Tuross, N. and Strathoples, L. 1993 Ancient proteins in fossil bones. Methods in Enzymology 224: 121-129. 